\title{
PENDAMPINGAN KONSELING SEKSUALITAS DAN KELUARAGA BERENCANA ALAMI (KBA) DALAM PERKAWINAN KATOLIK PADA CALON PENGANTIN DI GEREJA KATOLIK RATU ROSARI TANJUNG ANOM
}

\author{
Aprilita Br Sitepu ${ }^{1}$, Anita Veronika $^{2}$, Merlina Sinabariba ${ }^{3}$, Desriati Sinaga ${ }^{4}$, \\ R.Oktaviance ${ }^{5}$, Ermawati Arisandy Siallagan ${ }^{6}$, Risda mariana Manik ${ }^{7}$, \\ Bernadetta Ambarita ${ }^{8}$, Lindawati Simorangkir ${ }^{9}$ \\ 1,2,3,4,5,6 Prodi Diploma 3 Kebidanan STIKes Santa Elisabeth Medan \\ ${ }^{7}$ Prodi Ners STIKes Santa Elisabeth Medan \\ Email Korespondensi: aprilitasitepu6@gmail.com, anitaveronika09@gmail.com, \\ merlina.sinabariba@yahoo.com, desisinaga02@gmail.com, ria.ok88@gmail.com, \\ rmaariezandie.marpaung@gmail.com, risda.mariana@gmail.com, \\ detta_ambarita85@yahoo.com,lindasimorangkir79@gmail.com
}

\begin{abstract}
ABSTRAK
Perkawinan adalah wujud kasih Allah. Perkawinan adalah sarana berbagi kasih sayang secara kudus. Sakramen Perkawinan merupakan Sakramen tertinggi di Gereja Katolik. Tujuan dari pengabdian ini adalah untuk memenuhi kebutuhan peserta Kursur Persiaoan Perkawianan (KPP) dalam mempersiapkan diri untuk menjalani kehidupan pernikahan Katolik dan mampu memahami serta mengatasi masalah-masalah seksualitas dan Keluarga berencana (KB) selama menjalani hidup berkeluarga. Metode dalam kegiatan ini adalah dengan memberikan pemaparan materi dengan menggunakan laptoP, LCD dan leaflet. Hasil dari kegiatan ini adalah terdapat peningkatan epngatahuan calon pengantin setelah diberikan konseling ke seksualitas dan Keluaraga Berencana Alami (KBA) dalam perkawinan katolik. diharapkan dengan dilaksanakannya pendampingan konseling tentang seksualitas dan Keluaraga Berencana Alami (KBA) dalam perkawinan katolik pada calon pengantin di gereja katolik ratu rosari tanjung anom para calon pengantin dapat mempersiapkan diri untuk menjalani kehidupan pernikahan katolik dan mampu emngatasi masalahmasalah seksualitas, dan keluarga berencana alami selama menjalani hidup berkeluarga.
\end{abstract}

Kata Kunci : Pendampingan konseling, Seksualitas dan KBA, calon pengantin.

ABSTRACT

Marriage is an expression of God's love. Marriage is a means of sharing love in a sacred way. The Sacrament of Marriage is the highest sacrament in the Catholic Church. The purpose of this service is to meet the needs of the participants of the Persianoan Marriage Course (KPP) in preparing themselves to live a Catholic married life and be able to understand and overcome the problems of sexuality and family planning $(K B)$ while living a family life. The method in this activity is to provide material exposure using laptops, LCDs and leaflets. The result of this activity is that there is an increase in the knowledge of the prospective bride and groom after being given counseling on sexuality and Natural Family Planning (KBA) in Catholic marriages. It is hoped that with the implementation of counseling assistance on sexuality and Natural Family Planning (KBA) in catholic marriages for prospective brides at the Ratu Rosari Catholic Church, Tanjung Anom, the bride and groom can prepare 
Aprilita Br Sitepu,Anita Veronika, Merlina Sinabariba, Desriati Sinaga, R.Oktaviance, Ermawati Arisandy Siallagan, Risda mariana Manik, Bernadetta Ambarita, Lindawati Simorangkir

themselves to live a Catholic married life and be able to overcome sexuality problems, and natural family planning. during family life.

Keywords : Counseling assistance, Sexuality and KBA, bride and groom.

\section{PENDAHULUAN}

Sejak awal mula Allah menghendaki persatuan antara pria dan wanita, yang diwujudkan secara mendalam di dalam Perkawinan. Perkawinan ini dimaksudkan Allah untuk menggambarkan kasih-Nya, yaitu kasih dalam kehidupan-Nya sendiri sebagai Allah Tritunggal, dan kasih-Nya kepada manusia yang tak pernah berubah. https://www.kaj.or.id/dokumen/kursuspersiapan-perkawinan-2/hukum-gereja-mengenai-pernikahan-katolik)

Perkawinan adalah wujud kasih Allah. Perkawinan adalah saran berbagi kasih sayang secara kudus. Sakramen Perkawinan merupakan Sakramen tertinggi di Gereja Katolik. Sejak awal penciptaan, Allah sudah memberkati manusia melalui perkawinan, dengan diciptakannya Adam dan Hawa. (Komisi Keluarga KWI, 2015)

Sebelum mencapai kebahagiaan perkawinan, perlulah kita ketahui beberapa syarat untuk menjadikan Perkawinan sebagai perjanjian yang sah. Syarat pertama Perkawinan Katolik yang sah adalah perjanjian Perkawinan yang diikat oleh seorang pria dan wanita yang telah dibaptis, dan kesepakatan ini dibuat dengan bebas dan sukarela, dalam arti tidak ada paksaan, dan tidak dihalangi oleh hukum kodrat atau Gereja.

Secara sosial Kursus Persiapan Perkawinan (KPP) perlu karena kenyataan menunjukkan bahwa: beberapa keluarga mengalami kesulitan yang disebabkan kurangnya persiapan dalam perkawinan, banyak calon pengantin tergesa-gesa menikah tanpa bimbingan yang memadai, perkawinan bukan hanya urusan perorangan melainkan urusan masyarakat (sosial) dan Gereja.

Tujuan Kursus Persiapan Perkawinan memberi kepada muda-mudi bekal dalam hidup keluarga katolik, menambah wawasan dan pengetahuan mudamudi mengenai perkawinan dan hidup berkeluarga dari sudut pandang teologi, psikologi, moral, seksualitas, kesehatan, ekonomi, gender, dll serta KPP memberi pegangan bagi muda-mudi untuk mengambil tindakan dan mengatur hidupnya sendiri menurut azas moral kristiani. Kursus Persiapan Perkawinan memberikan harapan tercapainya keluarga yang baik, bagi Gereja dan masyarakat.

\section{MASALAH, TARGET DAN LUARAN}

Alasan kami memilih judul dan tempat ini kegiatan ini adalah Paroki Santa Maria Ratu Rosario Tanjung Selamat adalah salah satu paroki di Keuskupan Agung Medan yang berada di Jl. Flamboyan V No. 1/9Kompleks Polri, Tanjung selamat, Medan - 20134. Secara rutin pada hari sabtu minggu ke dua setiap bulannya diadakan Kursus Persiapan Perkawinan (KPP). 


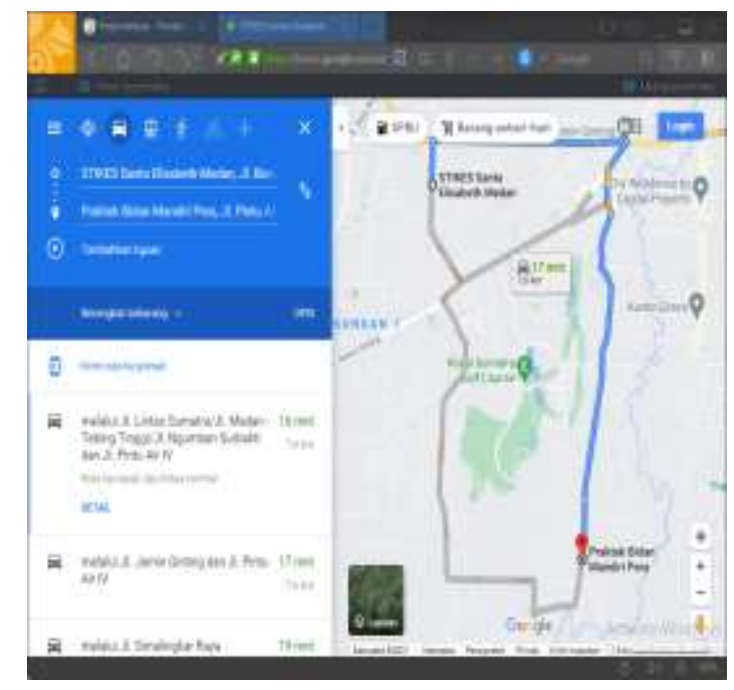

\section{METODE PELAKSANAAN}

a. Tahap Persiapan

Tahap persiapan pada kegaitan ini adalah dalam pembuatan pre planning, persiapan alat kesehatan yang digunakan, persiapan penyajian leaflet, tempat dan alat-alat lainnya disiapkan Paroki Santa Maria Ratu Rosario Tanjung Selamat.

b. Tahap pelaksanaan

Acara ini dilakukan dengan izin dari Pengurus Paroki Santa Maria Ratu Rosario Tanjung Selamat. Pelayanan ini dilakukan dengan memberikan penyuluhan kepada seluruh calon pengantin. Dilaksanakan pada pada hari sabtu minggu ke dua setiap bulan

c. Evaluasi

I. Struktur

Peserta hadir sebanyak 10 pasang (20 orang) calon pengantin di Paroki Santa Maria Ratu Rosario Tanjung Selamat. Setting tempat sudah sesuai dengan rencana yang dibuat dan perlengkapan yang dilakukan untuk penyuluh sudah tersedia dan sudah digunakan sebagaimana mestinya. Penggunaan bahasa yang digunakan komunikatif, pasangan calon pengantin memahami materi yang disampaikan.

II. Proses

Pelaksanaan kegiatan pada hari sabtu dan minggu ke dua setiap bulannya.

\section{HASIL PEMBAHASAN}

Metode pelaksaan dalam kegiatan Pendampingan Konseling Tentang Seksualitas Dan Keluaraga Berencana Alami (Kba) Dalam Perkawinan Katolik Pada Calon Pengantin Di Gereja Katolik Ratu Rosari Tanjung Anom pada hari sabtu dan minggu kedua setiap bulannya. Pelaksanaan penyuluhan ini ditujukan kepada calon pengantin. Media dan alat yang digunakan adalah leaflet.

Berikut gambar pelaksanaan kegiatan : 
Aprilita Br Sitepu,Anita Veronika, Merlina Sinabariba, Desriati Sinaga, R.Oktaviance, Ermawati Arisandy Siallagan, Risda mariana Manik, Bernadetta Ambarita, Lindawati Simorangkir

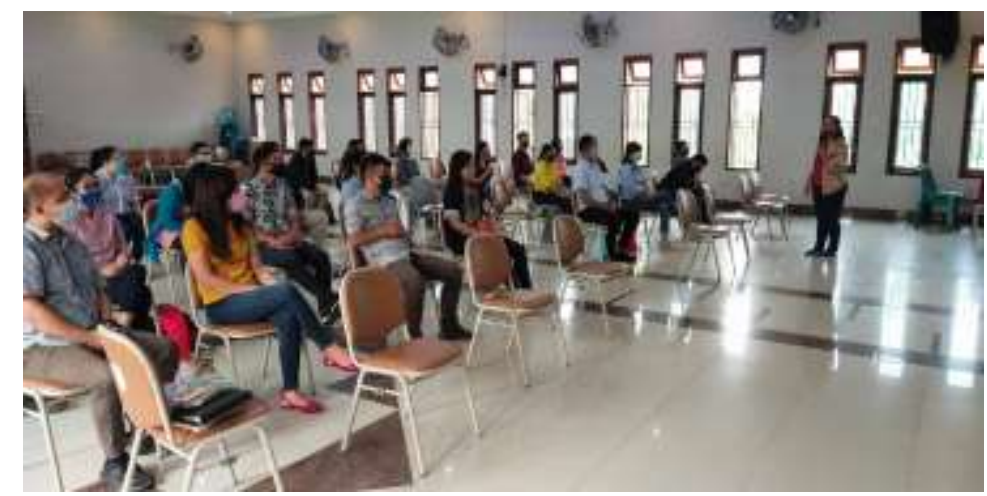

Gambar 1 : pemaparan materi Pendampingan Konseling Tentang Seksualitas Dan Keluaraga Berencana Alami (Kba) Dalam Perkawinan Katolik Pada Calon Pengantin Di Gereja Katolik Ratu Rosari Tanjung Anom

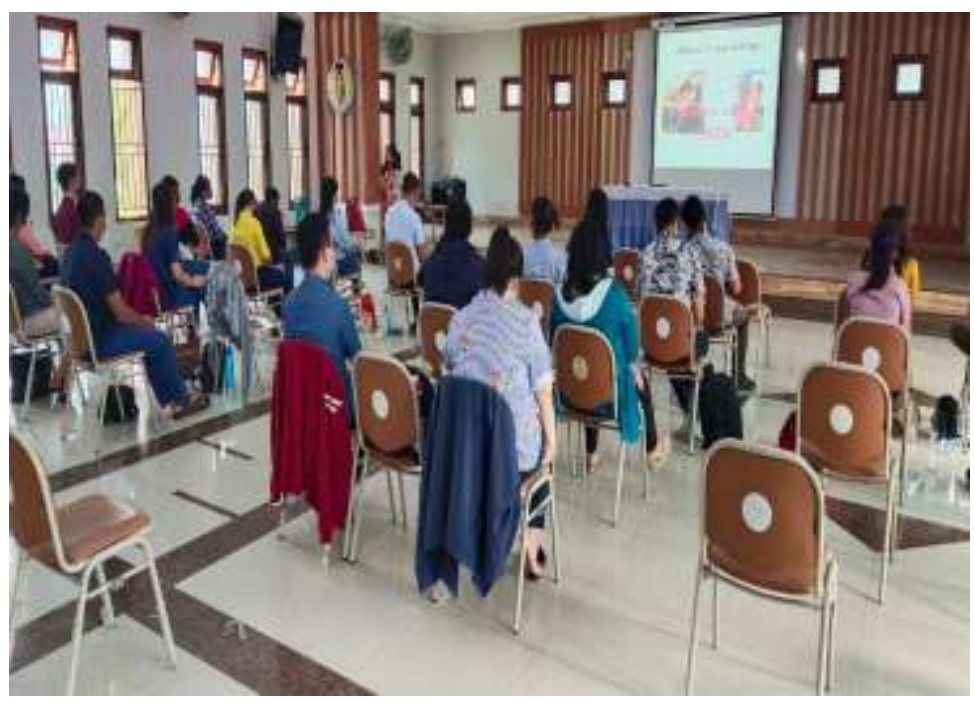

Gambar 2 : foto kegiatan PKM

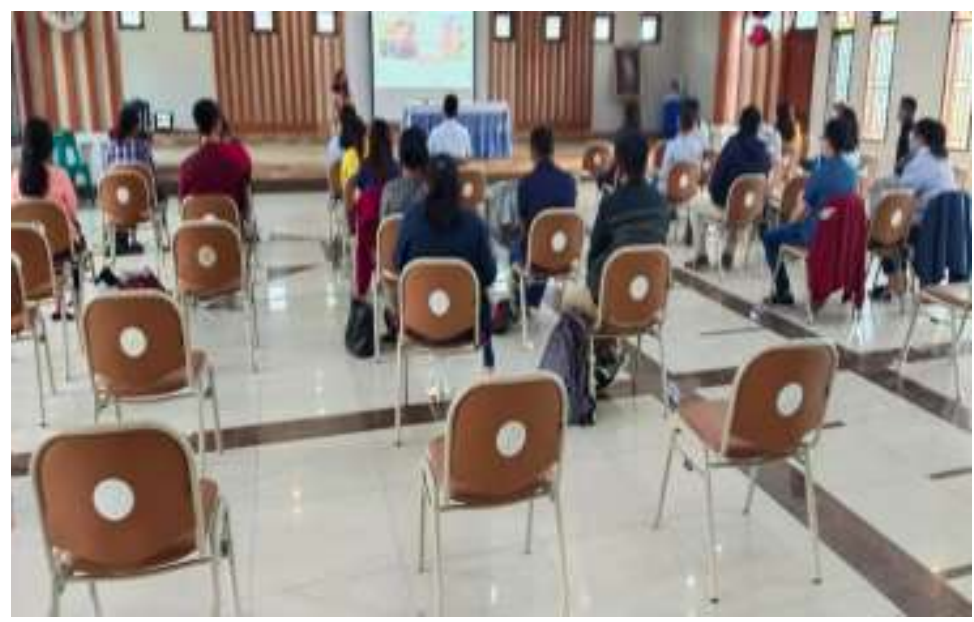

Gambar 3 : foto bersama calon pengantin 


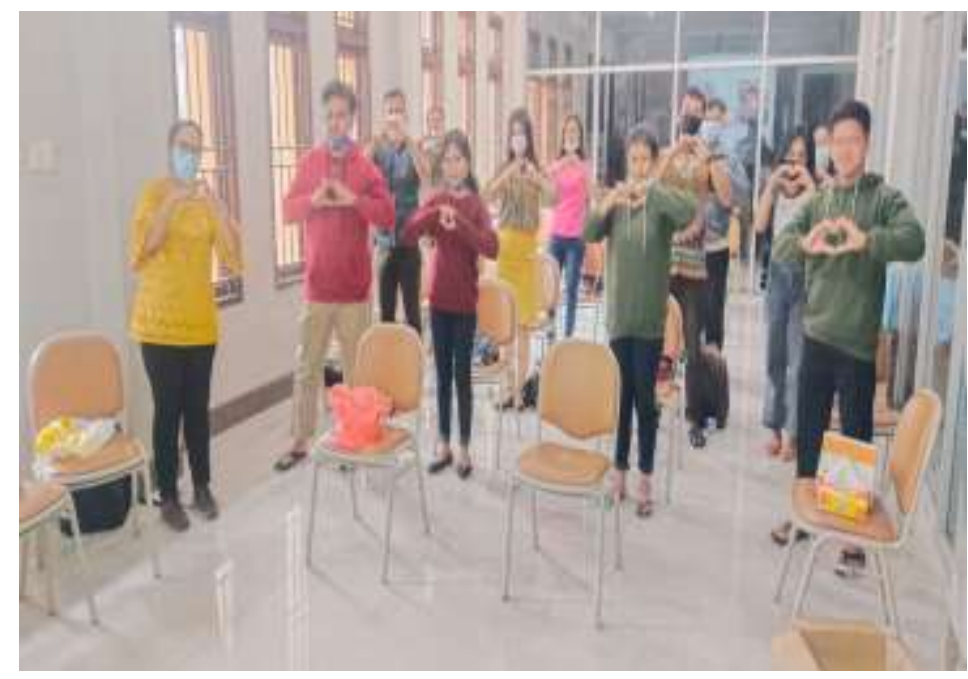

Gambar 4 : foto bersama calon pengantin

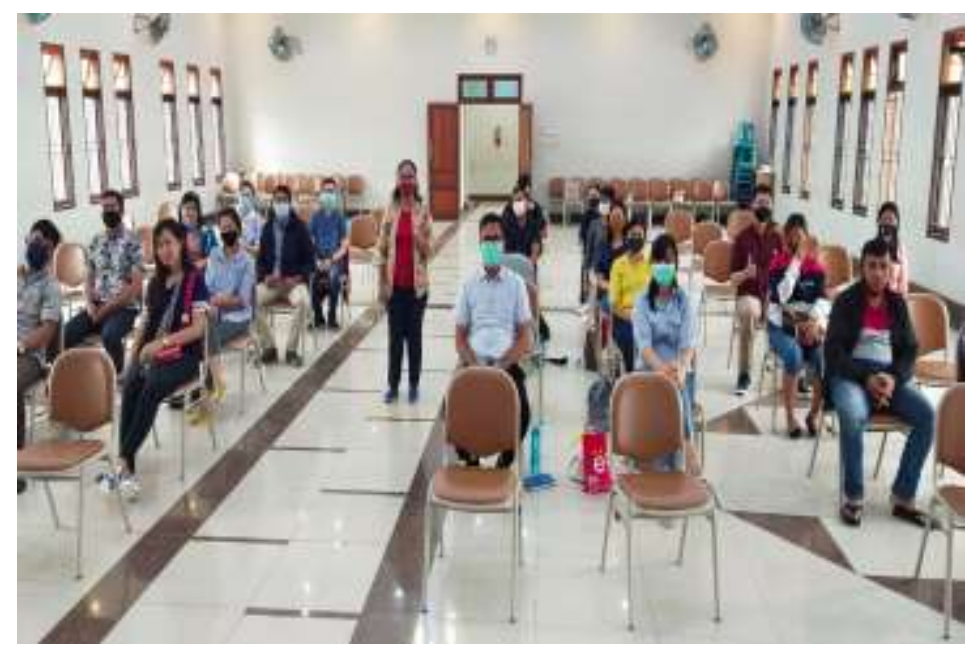

Gambar 6 : foto bersama calon pengantin

\section{KESIMPULAN DAN SARAN}

Pendampingan Konseling Tentang Seksualitas Dan Keluaraga Berencana Alami (KBA) dalam Perkawinan Katolik Pada Calon Pengantin di Gereja Katolik Ratu Rosari Tanjung Anom membantu para calon pengantin dalam mempersiapkan diri untuk menjalani kehidupan pernikahan katolik dan mampu memahami serta mengatasi masalah-masalah seksualitas dan Kelauraga Berencana (KB) selama menjalani hidup berkeluarga.

\section{DAFTAR PUSTAKA}

BkkbN, (2021). Usia Hamil dan Melahirkan Ideal Menurut BkkbN. www.riau.bkkbn.go.id/berita/1144, diakses tanggal 22 April 2021.

BKKBN. Keluarga Berencana Dan Kesehatan Reproduksi. Jakarta: BKKBN. 2017 
Aprilita Br Sitepu,Anita Veronika, Merlina Sinabariba, Desriati Sinaga, R.Oktaviance, Ermawati Arisandy Siallagan, Risda mariana Manik, Bernadetta Ambarita, Lindawati Simorangkir

Buku Materi Kursus Persiapan Perkawinan, Dekenat Jakarta Utara The Merck Manual, Seventeenth (Centennial) Edition, 1999 JNPK-KR dan STARH, Pelatihan Tehnologi Kontrasepsi Terkini (Contraceptive Technology Update), 2003 Medical Health Encyclopedia, Internet (http://www.healthscout.com/)

Eddy F. (2019). Pernikahan Usia Dini dan Permasalahannya. Bandung: Sari Pediatri.

http://www.katolisitas.org/mengapa-aborsi-itu-dosa/

http: //yohanessuparta.blogspot.com/2011/04/bahan-kpp.html

https://katekesekaumuda.blogspot.com/2018/04/moral-perkawinan.html

https://www.kaj.or.id/dokumen/kursus-persiapan-perkawinan-2/hukumgereja-mengenai-pernikahan-katolik

Komisi Keluarga KWI, Panduan Pelaksanaan Kursus persiapan perkawinan Katolik, Jakarta : Obor, 2015

Maria Gema Fautrigilyanan, ignasius S. S Refo Alf. Catur Raharso Pr (2006) Paham Perkawinan dalam Hukum Gereja KAtolik. Malang : Penerbit Dioma

Nita Evrianasari , Wahid Tri Wahyudi (2019) KIE REPRODUKSI DAN SEKSUAL BERBASIS ANDROID BAGI CALON PENGANTIN JURNAL KREATIVITAS PENGABDIAN KEPADA MASYARAKATO VOL 2, NO 2, 157-164

Notoadmojo. (2015). Pendidikan dan Perilaku Kesehatan. Jakarta: Rineka Cipta

Ralph C. Benson, Handbook of Obstetricks and Gynecology, 1971. (gambargambar) Katolisitas Indonesia, $2013 \mathrm{http}$ //katolisitas indonesia. blogspot.com/2013/12/ajaran-gereja-katolik-tentang.html

Sarwono Prawihardjo. (2018). Buku Panduan Praktis Pelayanan Kontrasepsi. Jakarta : Bina Pustaka

Sri Handayani. Buku Ajar Keluarga Berencana. Yogyakarta: pustaka Rihama : 2018 .H. 116-135.

Suratun, SKM. (2017). Pelayanan Keluarga Berencana Dan Pelayanan Kontrasepsi. Trans Info Media.

Theresia vita prodeita (2019) : Penghayatan Sakramen Perkawinan Pasangan Suami-Istri Katolik Membuahkan Keselamatan. Jurnal of Theology. Vol 8 No 1

UNDANG-UNDANG REPUBLIK INDONESIA NOMOR 16 TAHUN 2019 TENTANG PERUBAHAN ATAS UNDANG-UNDANG NOMOR 1 TAHUN 1974 TENTANG PERKAWINAN 